\title{
t $\begin{array}{ll}\mathrm{w} & 0\end{array}$ \\ Everyday Ritual in the Residential World
}

\author{
N. J. Enfield
}

Instead, then, of merely an arbitrary period during which the exchange of messages occurs, we have a social encounter, a coming together that ritually regularizes the risks and opportunities face-to-face talk provides, enforcing the standards of modesty regarding self and considerateness for others generally enjoined in the community.

\section{-Erving Goffman, "Replies and Responses"}

$\mathrm{T}$ his chapter is about everyday ritual in the residential world of the Kri, speakers of a Vietic (Austroasiatic) language of upland central Laos. I examine the relationship between the spatial layout of the Kri house and the everyday ritual behavior of the people in it. When inside a house, no matter whose house it is, a Kri person is not free to be just anywhere he or she likes. When carrying out everyday activities such as eating, working, sleeping, sitting, smoking, or talking, a Kri speaker may occupy space in a given house that is a function of that person's kin relation to the household and his or her status in terms of age and rank.

To give a simple preview of the phenomenon, figure 2.1 shows two Kri families relaxing, seated at the fire pit in the center of their houses' interiors. Their seating placement is not random but proper according to Kri norms. The man of the house sits toward the outer-upper corner of the fire pit (see fig. 2.2). His wife sits toward the inner-upper corner. The photographer, as guest, is properly seated farther toward the outer wall of the house. In this chapter I lay out the cultural logic of the Kri house floor plan in terms of inner, outer, upper, and lower dimensions and some ways in which Kri people ritually regiment their behavior (and that of others) in accordance with this logic. 


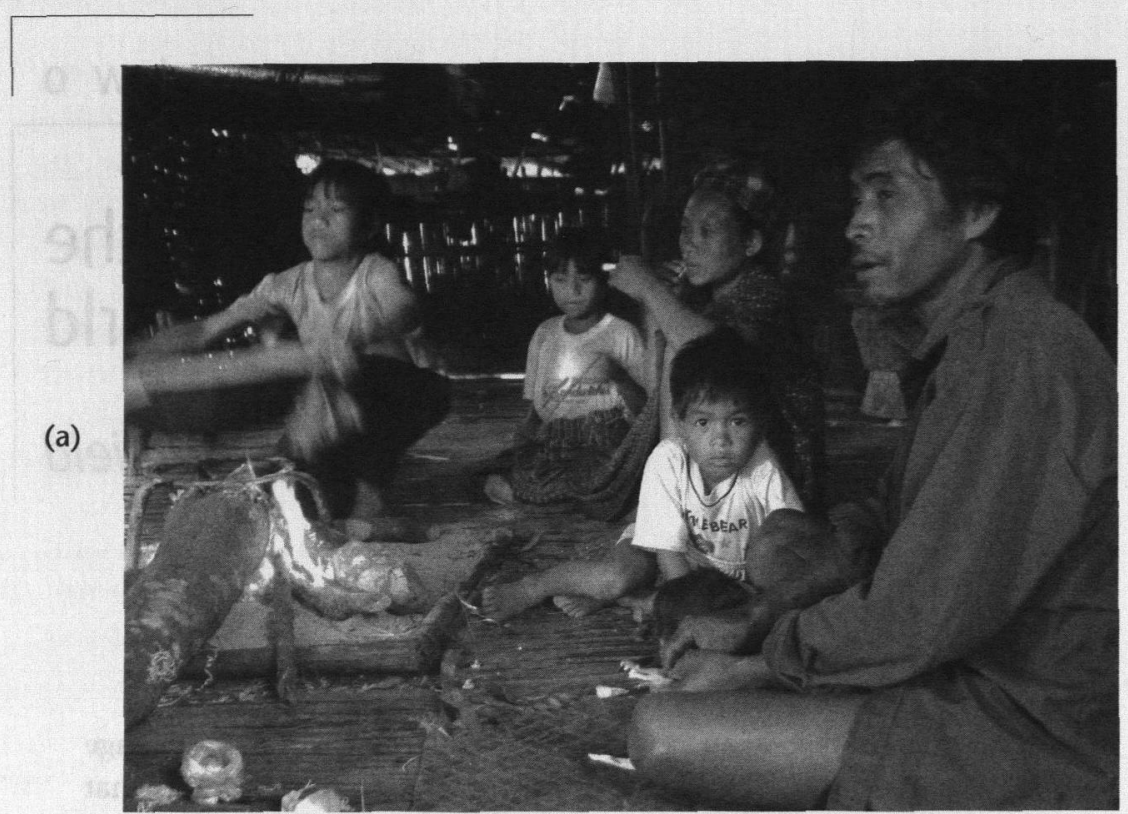

(b)

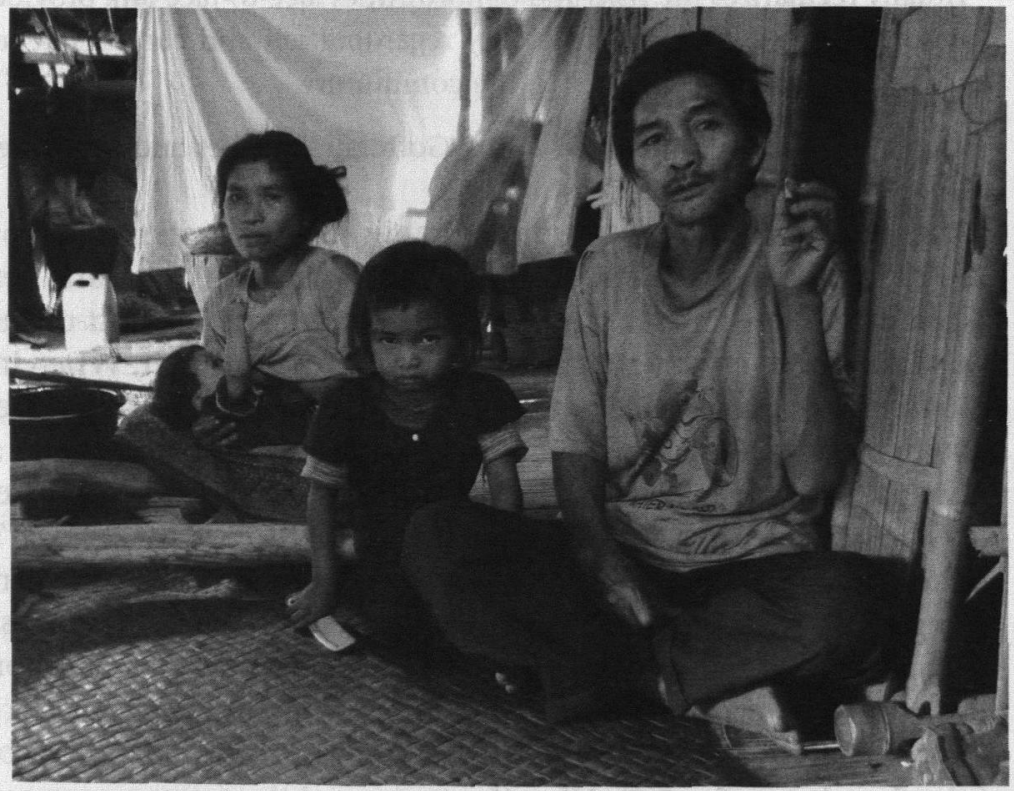

Figure 2.1. Members of two Kri families relaxing at home. The man of the house sits to the outer-upper corner of the fire pit, his wife sits to the innerupper corner. In both photographs, the man sits slightly farther in the "upper" direction. 
The ethnographic facts suggest some general properties of human ritual communication, whether it be in formal rituals such as weddings and initiations (Bloch 1974; Fortes 1966; Tambiah 1985) or in everyday rituals such as handshakes and observances of table manners (Goffman 1967; Leach 1966). Formal rituals and everyday rituals are not different species but, as is widely acknowledged, represent relative regions on a continuum. ${ }^{1}$ They share many of their important defining features. First, both formal rituals and everyday rituals are public behaviors concerned primarily with wielding influence in the social world. Their desired effects are brought about by affecting others' mental states and statuses. Because of this, the form or manner of those behaviors is constrained by the requirement that their meaning be recognizable to others. This recognizability is a general requirement of any social behavior (ritualized behavior most broadly construed; Huxley 1966a), but in ritual the manner of action becomes another sign in itself. Kinds of ritual can differ in the degree to which this formal component of the ritual behavior is thematized-that is, the degree to which it is a focus of attention or a consciously foregrounded feature of the current action.

Second, and relatedly, the formal behavior of ritual provides a public opportunity for moral assessment of the status and identity of participants. How well $\mathrm{I}$ am regarded as an Australian middle-class boy may depend in part on whether I keep my elbows off the table at dinnertime. My status as a Lao man may be judged in part on whether I have been ordained as a monk at some point in my youth, and if so, for how long. Others can use such behavior as a basis of (moral) assessment of me in terms of how well I inhabit my status and identity. Correspondingly, I can strategically display such behavior to exploit these normative patterns of assessment and thereby manage others' impressions of me (Goffman 1967; cf. Krebs and Dawkins 1984; Owings and Morton 1998).

\section{How Manner Meets Manners in Everyday Ritual}

\section{Manner: Formal Constraint for Recognizability and Evaluation}

Through formalization, ritual behavior is a way of acting in the world (Huxley 1966b: 258; Leach 1966: 403). As Leach pointed out, "rational technical" behaviors have brute means-to-ends relations (e.g., chopping down a tree), whereas both communicative behaviors (e.g., Englishmen shaking hands) and magical behaviors (e.g., swearing an oath) depend on social agreement to be effective. Although many researchers have wanted to distinguish firmly between the communicative and 
the magical in ritual (cf. everyday versus formal), Leach argued that any such distinction was "either illusory or trivial," and so the term "ritual" should embrace both categories. They are alike in that they operate not by natural law but by virtue of social agreement that they should so operate (Watts 1999). An example is money: "It is only given the institution of money that I now have a five dollar bill in my hand. Take away the institution and all $I$ have is a piece of paper with various gray and green markings" (Searle 1995: 27; see also Searle 1969: 51).

In order that these effects are possible, the actions by which we communicate must be sufficiently formalized to guarantee that the meaning of our behavior is recognizable to others. It is this recognizability alone that causes our communicative actions to work at all. This is true of nonhuman ritual behavior in the ethological sense. An example is the behavior of Labroides dimidiatus, a tropical fish that removes parasites from the bodies of other fish (Wickler 1966). Other fish make invitation displays before allowing the Labroides to feed on their bodies, and the Labroides also often does "a sort of dance" to elicit such invitation (Wickler 1966: 473). Nibbling on the bodies of other fish brings about the effects it does (the Labroides obtains food) by means of physically causal processes. By contrast, the efficacy of the Labroides' dance and of other fishes' gestural invitations depends on those actions being recognizable to the creatures involved (hence, as Wickler documents, the possibility of mimicking by other fish who attack the bodies of the submissive species instead of feeding on them). All of language, along with the rest of our symbolic resources, is predicated upon this notion of norm-governed recognizability of meaning (or action or intention).

The mechanistic requirement that ritual behavior be formally recognizable is a key conservative force in cultural practice generally. Accordingly, Sacks (1992) defined culture as "an apparatus for generating recognizable action." ${ }^{2}$ To effectively transform the world in a brute sense, one merely requires instrumental efficacy. If you want to break something, it doesn't much matter how you swing the hammer. But the communicative efficacy of a ritual action depends on its being socially recognizable by others as an instrument for its intended function. This constraint on form is thematized and exaggerated in formal rituals such as initiation rites, weddings, and political parades, where the defining actions need to be performed in just the right way if they are going to properly effect a social transformation (Austin 1962: 14ff.). As a result, social-cultural norms prescribe manner of action far more narrowly than would otherwise be required for purely instrumental purposes. A social task-be it requesting, complaining, telling, or grooming-is, 
and should be, done in a quite particular manner, even when doing it in that manner is not causally necessary to achieving its function. Hence the local cultural tweaking of even the most everyday actions. For example, we can often recognize locals just by the way they walk, sit, or smoke a cigarette. We are usually oblivious to it, but the locally conservative nature of our conforming social behavior imports a strong sense of ritual to everyday social action (Goffman 1959, 1967).

\title{
Manners: Ritual and the Cooperative Moral Order
}

Ritual behavior requires two things that are both puzzling in human evolution and definitive of our species: cooperation and moral order (see, among others, Axelrod 1984; Boyd and Richerson 2006a, 2006b; Danielson 1998; Joyce 2006; Key and Aiello 1999; Knight, Power, and Watts 1995). Human groups cooperate in maintaining the collective illusions necessary for sustaining the meaning of ritual: ${ }^{3}$

\begin{abstract}
Humans who participate collectively in magico-religious ritual performances do so precisely in order to instill belief in fictional "other worlds." Representations of such fictions are more than epiphenomenal; they are central in securing cognitive acknowledgement of an allegiance to the contractual intangibles underpinning cooperation in human social groups. Given the characteristically collaborative, cooperative nature of the rituals designed to generate such illusions, the "deceptions" which emerge may be dubbed "collective deceptions," corresponding to Durkheim's classic notion of "collective representations." (Knight, Dunbar, and Power 1999: 6; see also Knight, Power, and Watts 1995)
\end{abstract}

Knight and colleagues were referring to the kinds of illusions entailed by religious beliefs and associated rituals (e.g., entertaining the reality of souls without bodies and of objects with souls, "a counterfactual and counterintuitive world of supernatural agents" [Atran 2002: 4; see also Bloom 2004; Boyer 1994, 2002]). But nonmagical, nonreligious, everyday institutional facts, like all forms of symbolic meaning, are equally dependent upon collective illusion. The idea that a piece of paper with gray and green markings can be equal in value to vital food or medicine is one such illusion. So is the idea that the noise corresponding to the phonetic transcription [ $\mathrm{k}^{\mathrm{h}} \mathrm{t}$ ] is inherently connected with the essence of a feline. And so is the Kri idea that a son-in-law cannot approach the upper-outer corner of his father-in-law's house. Although the objects of these beliefs are not intrinsic, natural truths (no physical 
force literally prevents the son-in-law's movement), they nevertheless become true by virtue of being collectively, publicly treated as true. ${ }^{4}$

In this way, to engage in ritual behavior is to cooperate with one's group-mates in treating something as a natural fact when it is merely a social fact. This acquiescence to local convention is embodied in the observance of formal constraints on behavior and in the collective illusion (and attendant regimenting moral order) required to sustain them. We become constrained in our freedom to act, even in the most casual, everyday settings. Durkheim (1982 [1895]: 52) recognized this in defining social facts as "manners of acting, thinking and feeling external to the individual, which are invested with a coercive power by virtue of which they exercise control over him." As Knight wrote (1999: 234), ritual is inherently unfair. If I am a Nuer boy having my brow cut to the bone as I ritually transition to manhood (Evans-Pritchard 1940: 249), I might wonder why I wasn't born a girl. This is why ritual can be a political and a moral matter: political, because it invokes acquiescence to institutional facts, diminishing our individual agency (Kockelman 2007), and moral, because although ritual may not be fair, a person who does not acquiesce when he or she should is liable to sanction. And this moral sanction costs: "Moralistic punishment can stabilize any arbitrary behavior-wearing a tie, being kind to animals, or eating the brains of dead relatives ... when moralistic punishers are common, being punished is more costly than performing the sanctioned behavior" (Boyd and Richerson 2006b: 461).

All these arbitrary behaviors are ritualized in the more general sense of Leach (1966) and Huxley (1966b). Whether it's fair or not that as a Nuer boy I must let my brow be cut to the bone or that as a Kri son-in-law I must cower in the inner corners of my father-in-law's house, it's the right thing to do. If I am going to do the right thing, I have to "suspend doubt and simply follow the prescribed practices" (Tambiah 1985: 131). ${ }^{5}$ This is not unique to formal ritual. It comes with any collective illusion, including such innocuities as "It's good to say Please and Thank you" and "It's bad to approach the rồong of your father-in-law's house." And the very ideas of good and bad, at the conceptual core of moral value (Wierzbicka 1996), are themselves inherently institutional; that is, that such-and-such is considered good or bad in a culture is necessarily an arbitrary, institutional, collective illusion, because it could be otherwise.

Formal ritual is more easily seen as coercive than is everyday ritual (Bloch 1974). But everyday ritual is equally constraining. When Durkheim (1982 [1895]: 53) wrote of social "currents"-social facts not given by any explicit form of social organization-he said, "If perhaps I 
abandon myself to them, I may not be conscious of the pressure they are exerting upon me, but that pressure makes its presence felt immediately I attempt to struggle against them" (see also Wittgenstein 1953: \$1.129). We are seldom aware of being subject to coercion by tacit norms, just as we remain unaware of the air we breathe: "Thus air does not cease to have weight, although we no longer feel that weight" (Durkheim 1982 [1895]: 53). If we were to feel that weight, it might be enlightening (Whorf 1956: 209), but it might also be unbearable. Goffman vividly described the price paid by those who depart from normal or expected patterns of social conduct (Goffman 1963; see also Garfinkel 1967). Like formal ritual, everyday ritual "is not a 'free expression of emotions' but a disciplined rehearsal of 'right attitudes'" (Tambiah 1985: 134; see also Geertz 1966; Langer 1951). To sit in the right place in the Kri house is to display one's discipline. Yet unlike formal rituals, such everyday ritual practices do not thematize the formal discipline on display. The message is given off rather than given (Goffman 1959:2). Practicing the ritual indexes commitment to the collective norms and willingness to exercise the required self-discipline in a way that is publicly evaluable. ${ }^{6}$ As I show later, the discipline is regimented by cooperative adherence to normative practices.

\section{Summary: Everyday Ritual Is Where Manner and Manners Meet}

The key idea I want to draw from the foregoing discussion is the following: In all social communication, the manner in which an action is carried out is formally constrained by the requirement that it be recognizable to others as having the meaning it has. In ritual communication, of both the formal and everyday varieties, the manner of action is not merely instrumental in achieving public recognizability of the action's meaning. It is also itself made available for evaluation as a token of the actor's acquiescence to a constraint of social convention. Ritual is then a site in which the local moral order is displayed, exercised, and no doubt contested. In formal ritual, this evaluable manner of action tends to be a focus of attention, whereas in everyday ritual it tends not to be. But the coercive and regimenting nature of everyday ritual comes readily to the surface when the constraints are contravened.

\section{Kri Residence}

The Kri are a group of about 250 people living in the upper reaches of the Nrong Valley, in a protected rainforest in the easternmost area of 
Nakai District of Khammouane Province, Laos. They live within a day's walk of the Vietnamese border at Ha Tinh Province. The Kri language belongs to the Vietic sub-branch of the Austroasiatic language family (Enfield and Diffloth 2009).

In this section I describe the Kri house and its meaning in Kri daily life, looking particularly at the way people engage in practical interpretation of its meaning, regimented by the moral constraints of everyday ritual.

\section{Plan of the Kri House}

As is the case in any other culture, the spatial layout of the Kri house is charged with social meaning. The house "serves as much to reveal and display as it does to hide and protect..., the physical structure, furnishing, social conventions and mental images of the house at once enabling, molding, informing and constraining the activities and ideas which unfold within its bounds" (Carsten and Hugh-Jones 1995: 2; see also, among others, Bourdieu 1990: 271ff.; Duranti 1981: ch. 4; Frake 1975; Lévi-Strauss 1963: ch. 8, 1987; Waterson 1990). The Kri word for house is krnooq (derived from kooq 'to live, remain, be somewhere', with infixation of the nominalizer $-r n$-). The design of all Kri houses follows a standard, modular plan. The house is built entirely by hand, using machetes and no other tools. Materials are available exclusively from the forests surrounding the village: timber of various gauges for the main structure, varieties of bamboo for flooring, walls, and light structure, varieties of rattan for tying the structure together (no nails are used), and umbrella-size leaves of the culoo palm (Licuala grandis) for thatching. Houses differ in size as a function of individual necessity and motivation. A man may be more or less interested in having a large house. He might or might not want certain optional features such as a covered verandah in addition to an open-air verandah, or indeed, any kind of verandah. Numbers and sizes of internal partitioned rooms also differ, but the general layout is always the same.

The floor plan of the Kri house interior is basically a square, onto whose two dimensions are mapped kinship (inner-outer) and social rank (upper-lower). Another way to think of it is that the house has four sides: upper, lower, inner, and outer. Figure 2.2 shows the plan of the house in which I stayed during field trips in 2005 and 2006. The house is fairly complete by Kri standards, featuring both a covered verandah and an open verandah.

Social meaning is mapped onto the floor space by a simple organizing principle that crosses an inner-outer with an upper-lower axis. These 


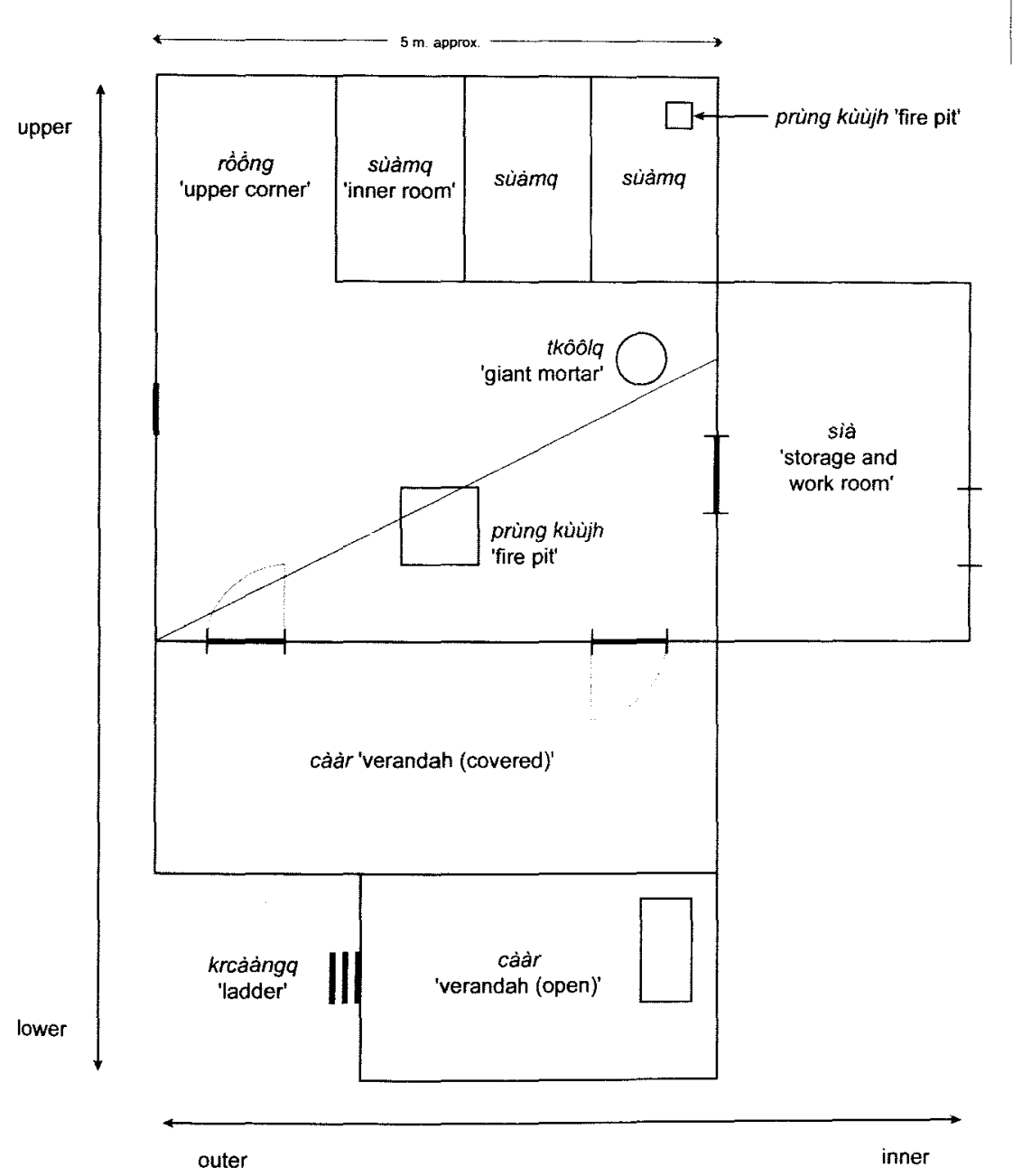

Figure 2.2. Plan of a typical Kri house.

two axes more or less map onto a distinction of "in" versus "out" of a kin circle and "high" versus "low" on a scale of rank, defined by age and other indices of status. The lower side of the house is the side where people enter and exit. (There is no other passage in or out.) The lower side might be termed in English the front of the house. The upper side is the side farthest from the entrance. It corresponds to what would be called in English the back of the house. The upper-lower axis of the house is typically aligned with an up-down axis in local physical space, either the upstream-downstream orientation of the nearest river 
or stream or the uphill-downhill orientation of the land on which the house is built (or both, since these are usually aligned with each other).

Along the left-right axis as one enters the house, the inner side is the side of the house where family activities such as pounding rice (at a giant mortar, labeled $t k \hat{o} o ̂ l q$ in figure 2.2), husking corn, and preparing and storing food take place. ${ }^{7}$ A storage and work room called the sià is attached to the main structure of the house on this side.

The outer side is where non-kinfolk should be. Certain signs make it publicly clear which is the outer side. The ladder up onto the house leads up on that side, and inside the house are other clues, such as the clear space called the rồng in the upper-outer corner and the large diagonal beam running down along the roof, which joins the lower (front) wall of the house at the outer-lower side entrance.

The house has a third spatial dimension as well: the vertical dimension, or above versus below. The Kri house is literally raised above ground level, as shown in figure 2.3. For talking about the various spatial relations within the house, Kri speakers use the following spatial terms:
Above, upstream
tồồ 'above, upper, upstream place' lêeh 'there (above, upstream)'
saaw 'ascend'
Below, downstream tìk 'below, lower, downstream place'
cồò 'there (below, downstream)'
cì̀ 'descend'
Across (in-out) seeh 'there (across ways)'

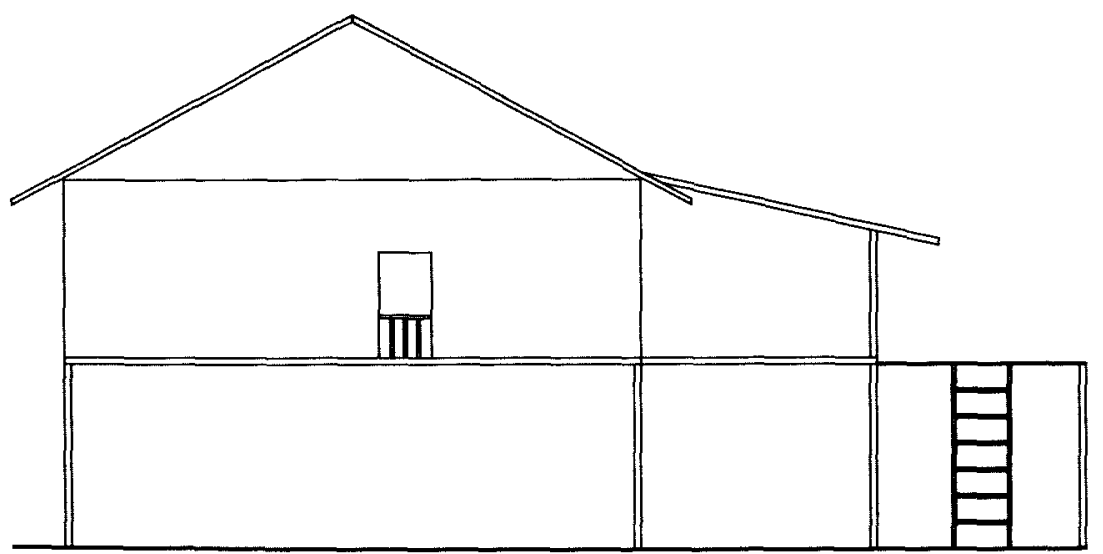

Figure 2.3. Elevation of a Kri house, looking from the outer side-that is, from the left of figure 2.2 . 


\section{Social Aspects of the Kri House}

The house plays a central role in Kri social organization. For one thing, it is where a great deal of social interaction takes place-where meals are shared, where gossip is exchanged, where stances are contested, where bonds are built, maintained, and eroded. In addition, the house has a special status in terms of kinship organization. Kri kinship is anchored in kmuuc krnooq 'spirits of the house', which belong to the man of the house. Each person belongs to the spirits of a single house, as determined by who owns the spirits of the house into which one is born (this may be one's father or grandfather). When formal rituals are performed for these spirits, as happens a few times a year, the rituals take place around a tiny, ceremonial fire pit located in the inner-uppermost corner of the house interior (fig. 2.2).

A man's house spirits are not necessarily located physically in his own dwelling. For example, as a young man's nuclear family grows, he may build his own house and move to live there with his family while his father is still alive-as usually happens, given the physical constraints of houses. Because the son does not have his own spirits in his house, it is considered not a real krnooq 'house' but merely a tuup 'hut', despite its being structurally identical to a house.

The structure shown in figure 2.4 (top) is regarded as a real krnooq 'house'. It has its own spirits. Accordingly, there is a tiny fire pit in the innermost room (sùàmq; see fig. 2.2). The structure in figure 2.4 (bottom) belongs to a son of the man who built the first house. The Kri insist that the son's dwelling is not a real krnooq but a tuup, using the word for a simple little raised hut in the rice fields (fig. 2.5). Accordingly, although the house is fully functional, it has no such tiny fire pit in the inner sanctum. When the son, along with his family, performs formal rituals to his kin spirits, he does so in the father's house.

The use of the word tuup for the house in figure 2.4 (bottom) is an example of the everyday collective illusion that defines ritual and other symbolic behavior for Knight, Dunbar, and Power (1999). To insist that the son's house in figure 2.4 is a "hut" is to ritually suspend the normal way of talking. It may be compared to any kind of avoidance behavior, such as using the word "mask" for "face" in fox-hunting, or avoiding words that sound like the names of recently deceased persons (see Dixon 1971). 


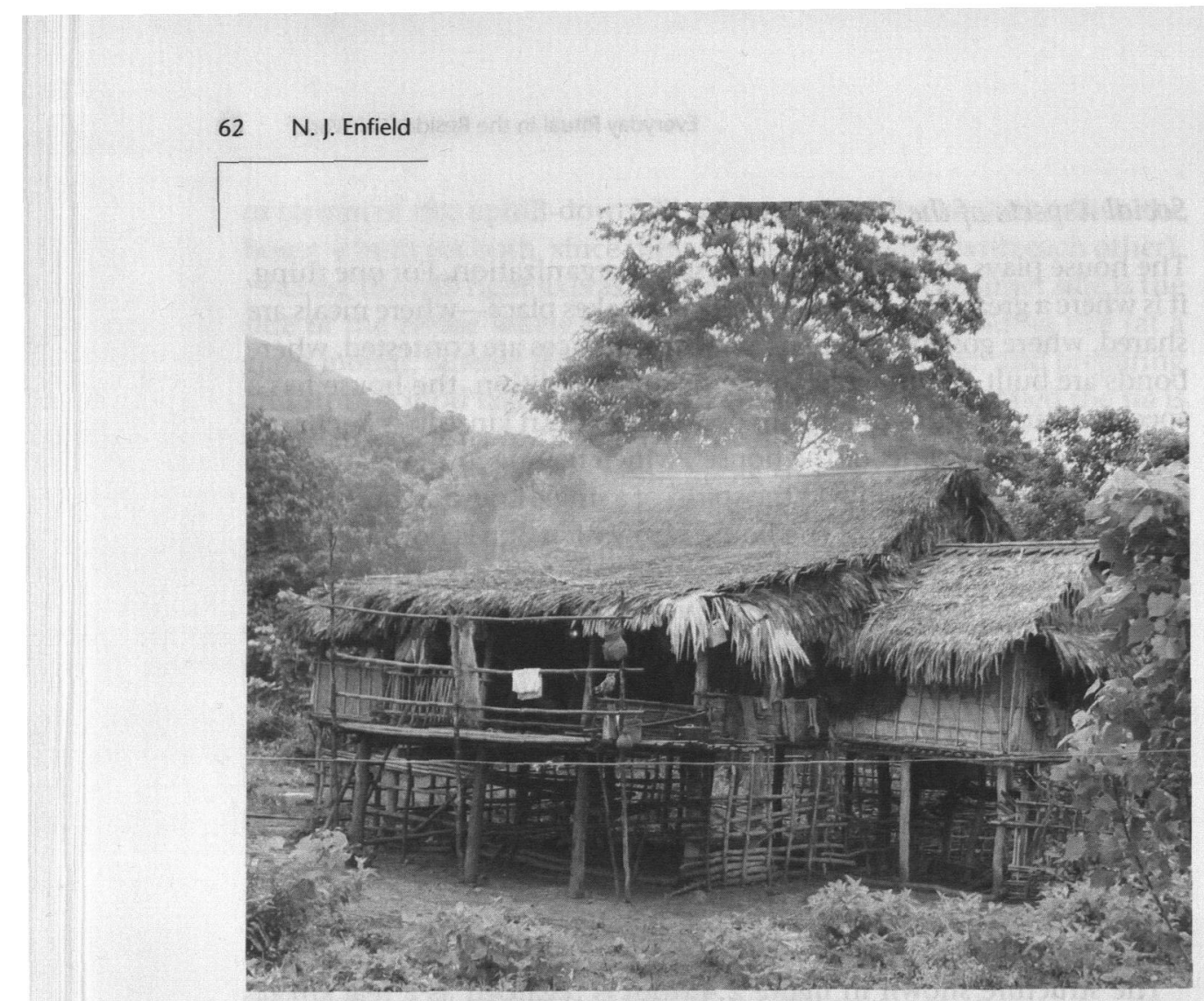

(a)

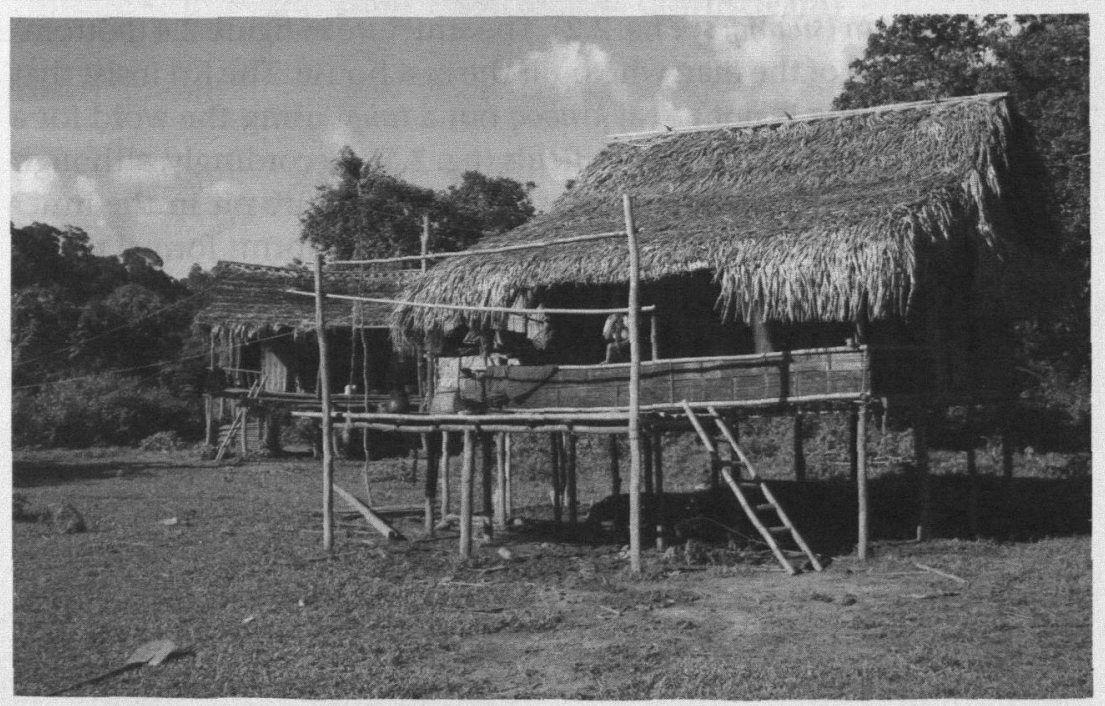

(b)

Figure 2.4. Father's house (top) and son's house. 


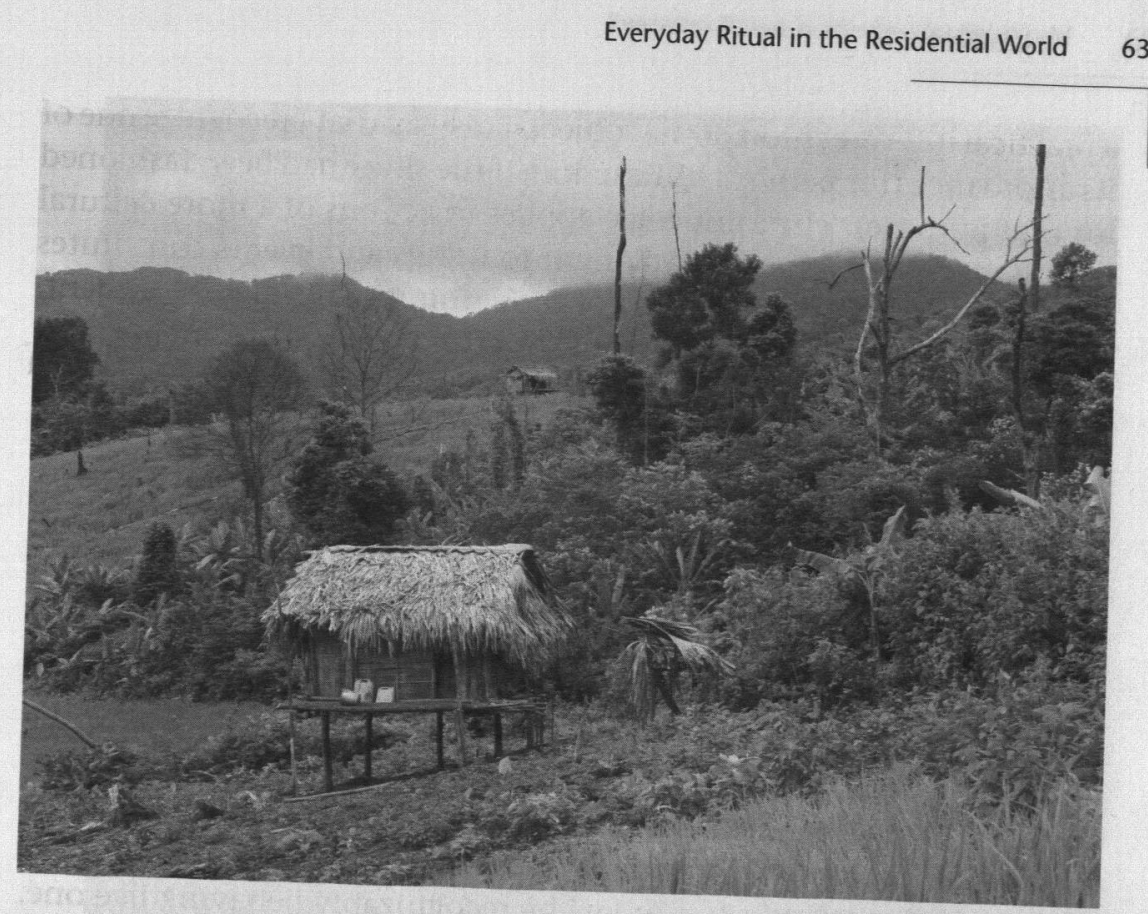

Figure 2.5. The usual referent of tuup 'field hut'.

\section{Practical Interpretation of the Kri Residence: Behaving in Accordance with Norms}

Kri people's daily behavior surrounding the house constitutes a domain of everyday ritual in which members of the community constantly display their cooperation with morally sanctionable social norms. Adhering to these constraints is, on the one hand, a product of these norms (i.e., the norms are what cause the behavior) and, on the other, a way of bringing about or reinforcing the norms, by instantiating the normative behavior and thereby producing public signs that those norms apply. The norms are further reinforced when their contravention results in public sanctioning behavior, which involves thematization and explicit articulation of the normative practices and their meaning.

I use the term "practical interpretation" to refer to people's behavior insofar as it constitutes evidence of their understanding of meaning in the physical world (Kockelman 2006). If I take a key and open a locked door with it, these actions constitute a display of evidence to any onlooker that I know what these instruments are for (i.e., what their designers had in mind by designing them) and what may be achieved by their use. Similarly if I pick my teeth with a sliver of bamboo, I display 
a practical interpretation of that object. I display that I recognize one of its affordances (or perhaps its function, if the sliver had been fashioned for that purpose). The same logic applies to actions of a more cultural nature. In general, the way we orient to things and events constitutes (evidence of) our understanding of those things. This may be evident, for example, in the physical world of affordances, instruments, and actions or in the cultural world of language, culture (roles, identities), and social interaction (Kockelman 2006; Sacks 1992). The spatial layout of the Kri house has meaning in this sense. Behavior that is oriented to the house in particular ways constitutes a range of interpretants of the house, and thereby a practical interpretation. ${ }^{8}$

Physical behavior not only supplies an interpretation of what the house means but, more important, expresses an individual's commitment to and identification with social categories (roles and identities) that are implicated in those meanings. As a son-in-law, when I cower in the inner corner of my father-in-law's house, I am not just being a son-inlaw, I am "doing" being a son-in-law (see Sacks 1992: 215ff.). I do what sons-in-law do, and in doing so I display that I am a (good) son-in-law. I categorize myself as a son-in-law by recognizably behaving like one. And the cause-and-effect relationship goes both ways: I act like this because I am a son-in-law; I am (categorized as) a son-in-law because I act like this.

Goffman (1963: 2) observed that "society establishes the means of categorizing persons and the complement of attributes felt to be ordinary and natural for members of each of these categories." We have, then, roles such as matààm 'son-in-law' and identities such as Kri 'of Kri ethnicity' (Kockelman 2006). "We lean on these anticipations that we have, transforming them into normative expectations, into righteously presented demands" (Goffman 1963: 2). ${ }^{9}$ It is the business of ethnographers (for types of roles or identities and for types of relationships implied by these) and biographers (for individuals and relationships between individuals) to define what constitutes such normative expectations in a community.

I now turn to some of the everyday ritual constraints that Kri people are subject to. A first phenomenon is the forbidding ( $k$ ềेl 'taboo') of certain people, at certain times, from going up into certain houses at all. For instance, when a women is menstruating, she is not to ascend any house but must 'stay down below' (kooq qùù tìk cồohh) or 'stay down on the ground' (kooq qùù qatak cò̀ồ ). At these times she sleeps in a separate menstruation hut (fig. 2.6). 


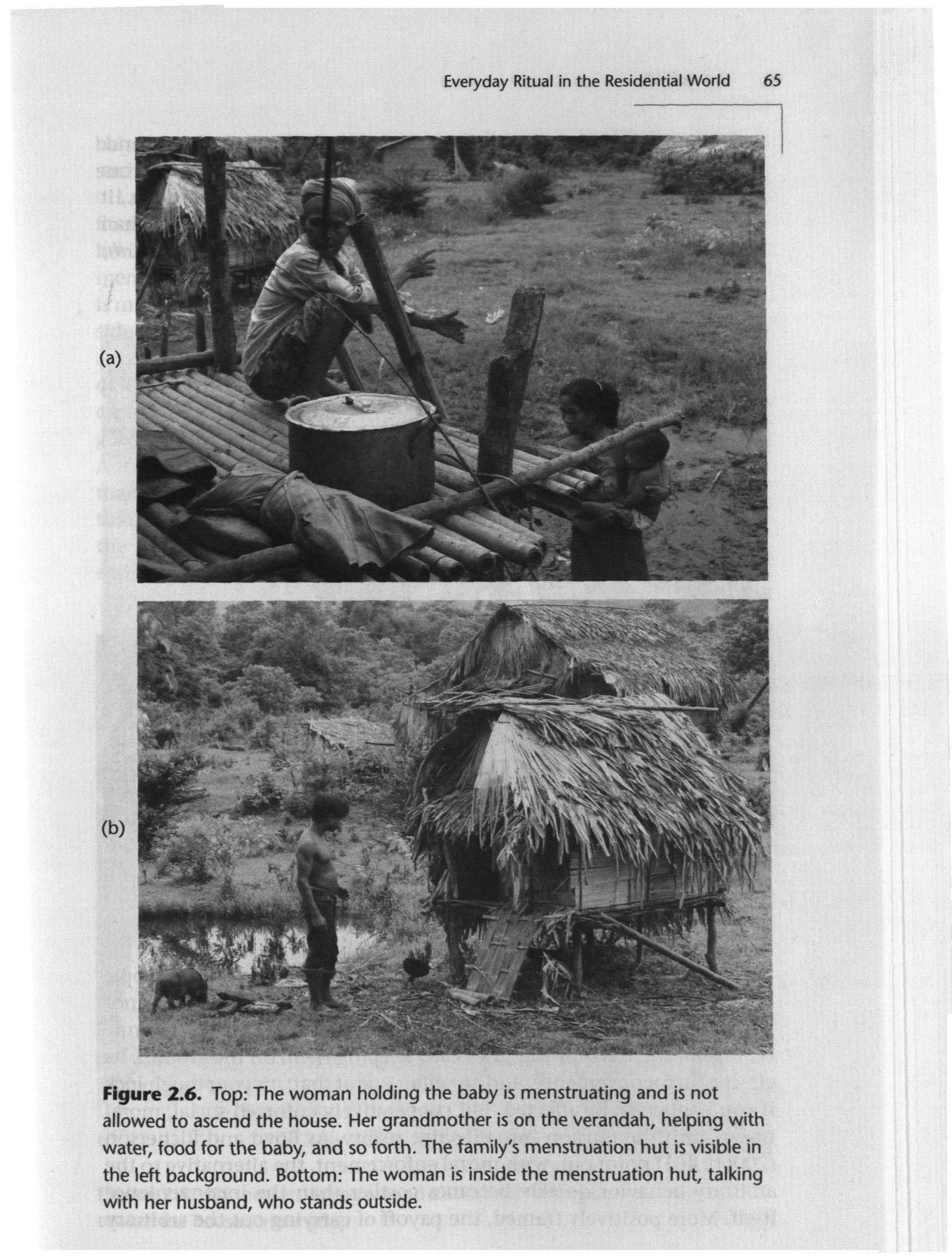


Other forms of contamination can keep people down on the ground. For instance, the man pictured in figure 2.7 is contaminated from assisting with a childbirth some days earlier. He is not allowed (i.e., it is kềel 'taboo' for him) to ascend any house in the village other than his own house until such time as his contamination is resolved (qapirrh) by formal ritual.

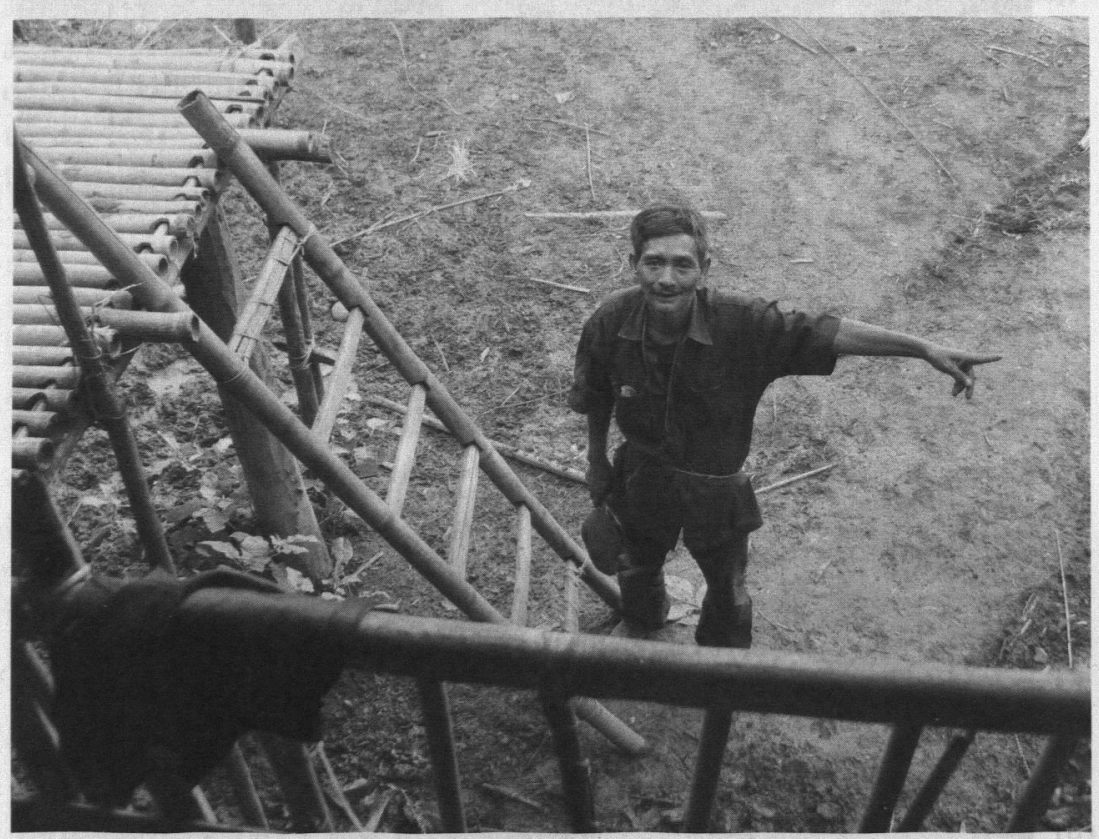

Figure 2.7. This man is contaminated because of having assisted during a childbirth some days prior. He cannot ascend another's house until his contamination is ritually resolved (qapirrh).

These are examples of the kinds of inconvenience to which people acquiesce on the basis of collective illusions about what can or cannot happen and what might happen as a result. The substance of the rule is illusory; there is nothing physically keeping them on the ground. Its effect is an inconvenience, and an unfair one at that: it's your tough luck if you happen to be affected. But cooperatively enforced social, moral norms turn the illusion into effective reality. As Boyd and Richerson (2006b: 461) point out, with moral enforcement, the alternative to the arbitrary behavior quickly becomes costlier than the inconvenience itself. More positively framed, the payoff of carrying out the arbitrary 
behavior is the opportunity to be judged a good person in terms of roles such as son-in-law or identities such as Kri.

I now turn to normative Kri practical interpretation of the house's floor plan. The inner side is where family members tend to reside, where housework (winnowing, pounding rice, etc.) takes place, where family members eat, and where they enter and exit the house. The outer side is more for non-kin, that is, guests. Women tend to sit toward the inner side of the house, and men, toward the outer side. On the upper-lower axis, people of higher status tend to sit toward the upper side, and those of lower status toward the lower side. By these criteria, it is often crystal clear where certain individuals ought to be. For example, a high-ranking guest who is not a family member sits toward the upper-outer corner. A son-in-law sits toward the inner-lower corner. The high rank of the man of the house tends to position him farther toward the outer side than his female housemates. An illustration of these principles concerns the problem of where in the house to place kamàng 'tray tables' for eating (fig. 2.8).



Figure 2.8. Kri speakers eating around a kamààng 'tray table' (here, placed toward the house's inner side). 
On a normal day during my fieldwork, the tray table at which I ate, always separately from my hosts, was placed on the floor on the outer side of the house, while the household's tray tables were placed toward the inner side. My tray table was typically placed slightly higher-that is, slightly more toward the upper side-than the family's tables. This placement accorded with my status as non-kin (outer) and honored guest (upper).

A case illustrating the principle of respecting the mapping of outerinner in terms of guests versus insiders arose when I visited a house while other visitors were also present. Food was served, and four tray tables were laid out across the house along the outer-inner axis. From outer side to inner, the groups seated at these tables were (1) the ethnographer and his official Lao government associate, (2) the man of the house, his son, and a Vietnamese hiker-trader guest, (3) the woman of the house, her daughter, and her niece, and (4) the son-in-law and his wife (fig. 2.9). The last two sat out in the sià itself.

The occasion depicted in figure 2.9 was purely informal. Other kinds of functional contexts result in other kinds of configurations. Figure 2.10 shows a different occasion on which I observed four tray tables laid out in a line, this time during a formal ritual called qjàk sii 'tying of (string on) the arms' (related to the Lao ritual called basii). The key event in this ritual is the tying of cotton strings around the wrists of an individual or members of a small group. The ritual is carried out ad hoc under a range of circumstances, such as a farewell, a return to good health after illness, or the death of a relative. A small number of people are targets of the ritual and have the strings tied around their wrists, one by one, by the many other participants present. Those who ritually tie the strings on the guests of honor do so as a kind of wellwishing, and these people may be anyone from children to seniors, kin to outsiders. Associated with the string-tying component of the ritual event is eating and drinking. Because this is a formal ritual, the eating is ceremonial-that is, everyone has already eaten dinner at home earlier, and (unlike in the scene illustrated in fig. 2.9) the central goal of the event is not that everyone be full until the next meal. Those who are given food are the honored, respected guests, and naturally they are seated in the outer half of the house. In contrast to the layout of four tray tables for an everyday meal, in this case the tray tables were laid out not across the house but along the upper-to-lower axis, lined up on the outer side of the house (fig. 2.10).

This arrangement accorded with the food-giving of the event's being oriented exclusively to guests; hence all tray tables were on the house's 
(a)

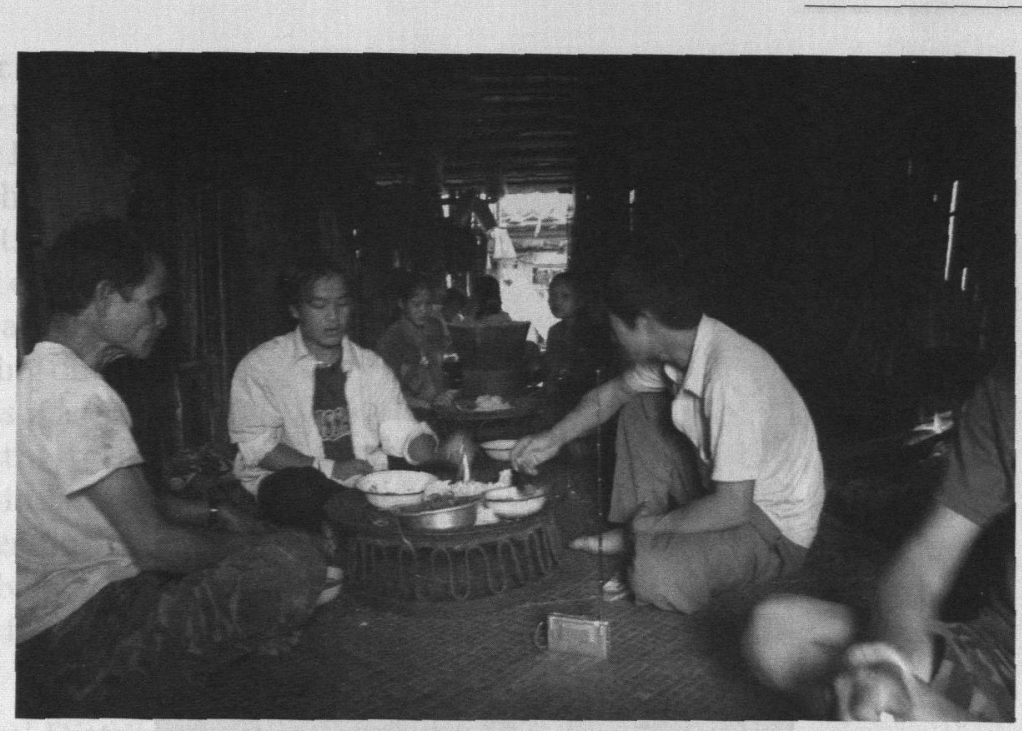

(b)

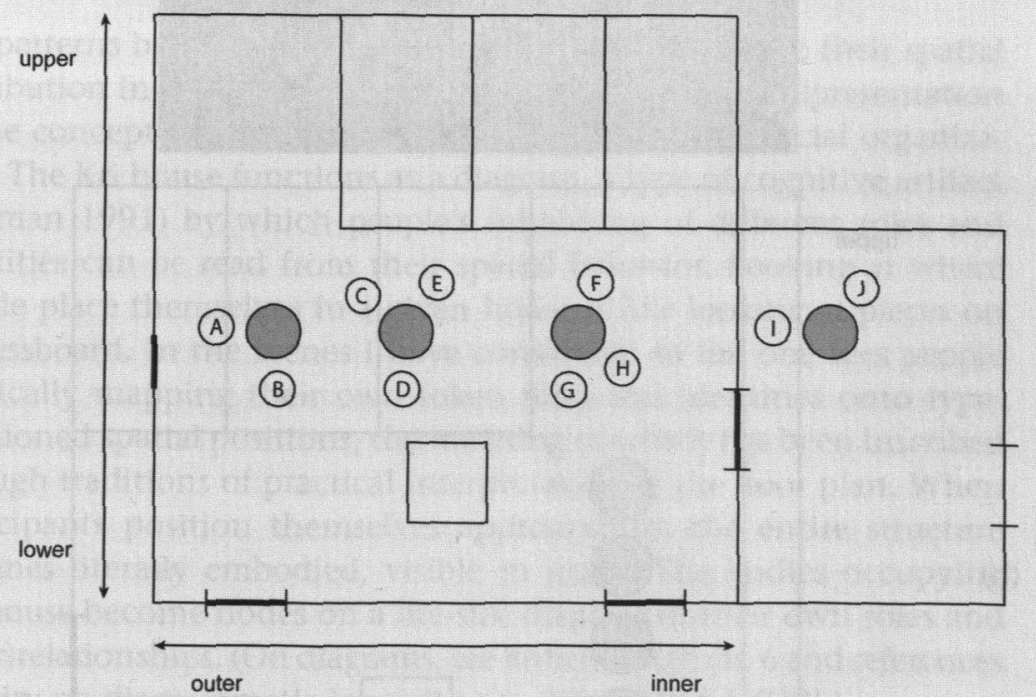

Figure 2.9. Layout of four tray tables, across the house, from outer side (foreground in photo) looking toward inner side. The people are (A) ethnographer (not shown in photo); (B) government chaperone of ethnographer (arm and knee visible to right of frame); (C) man of the house (leftmost in frame), (D) Vietnamese hiker-trader, passing through (next to his radio set), (E) C's son, (F) C's daughter, (G) C's wife, (H) C's niece, (I) C's eldest daughter, and $(\mathrm{J})$ I's husband and C's son-in-law (visible in far background of photo). 
(a)

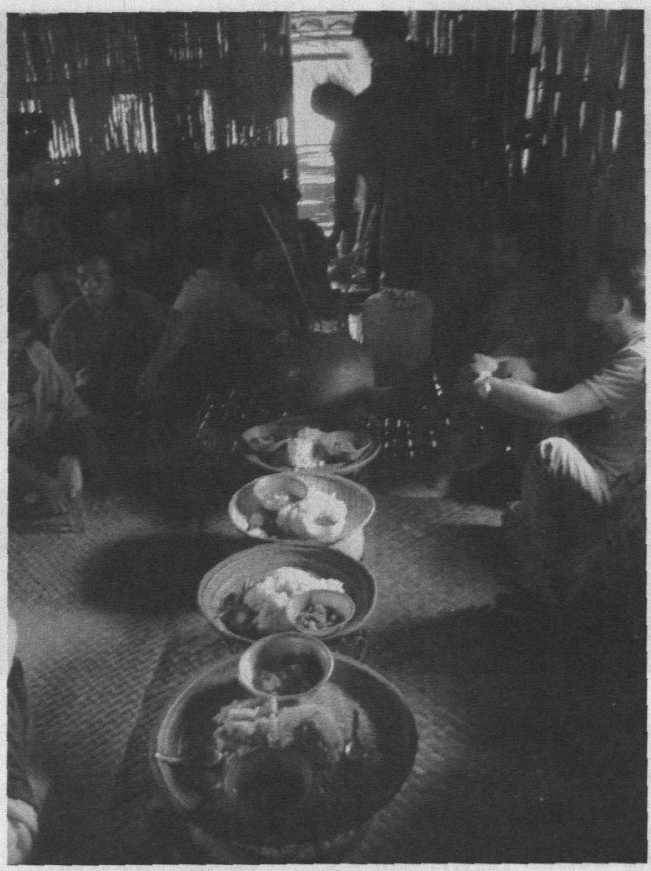

(b)

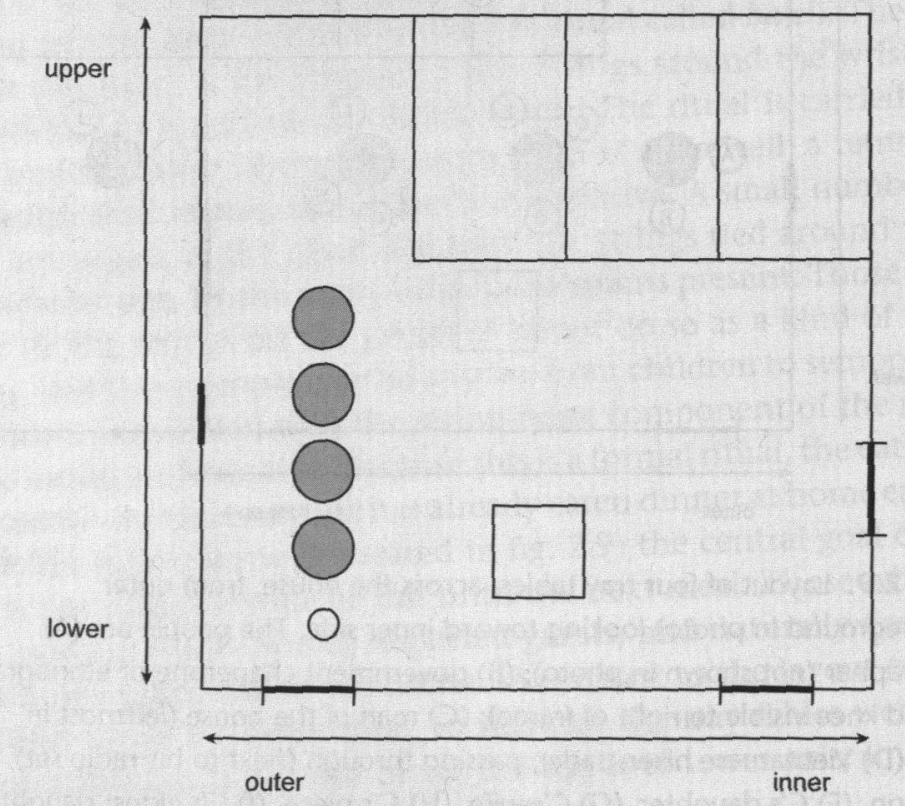

Figure 2.10. Tray tables laid out vertically on the outer side of the house for ritual eating during a qjàk sii 'string-tying' event. 
outer side. Within that placement, the seating of guests at each tray table was arranged from lowest to highest rank along the lower-upper axis. Naturally, the guests of honor-in this case, the ethnographer and his government sidekick-were seated at the uppermost of the four tray tables.

An earthen jar called boom $q$ in Kri-visible in the photograph in figure 2.10 at the far end of the row of tray tables, with long bamboo straws sticking out of it-was full of brewed liquor, to be drunk after the eating. It was placed at the lower side of the house, a best compromise given that the practice of drinking must incorporate everyone, including sons-in-law, who would be forbidden from entering the upper-outer corner. Such festivities invariably evolve into long drinking sessions involving men of all ranks. ${ }^{10}$ The upper-outer quadrant (rồng) remains clear for guests to relax in.

\section{Spatial Distributions and Diagrammatic Iconicity}

The patterns by which people in the Kri world regularize their spatial distribution in the house provide an external, physical representation of the conceptual structure underlying norms of Kri social organization. The Kri house functions as a diagram, a type of cognitive artifact (Norman 1991) by which people's inhabiting of different roles and identities can be read from their spatial behavior. Looking at where people place themselves in a given house is like looking at pieces on a chessboard. In the scenes I have considered so far, one sees people physically mapping their own token roles and identities onto typesanctioned spatial positions, the meaning of which has been inscribed through traditions of practical interpretation of the floor plan. When participants position themselves appropriately, the entire structure becomes literally embodied, visible in space. The bodies occupying the house become nodes on a life-size diagram of their own roles and (inter)relationships. (On diagrams, see Enfield 2009: ch. 6 and references therein; on diagrammatic iconicity, see Peirce 1965 [1932].)

\section{Sanction of Norms: Making the Tacit Explicit}

Just as people's actions constitute evidence of the way they interpret the world around them (Kockelman 2006), so do their words. Most of the time, when life runs as it should, patterns of everyday ritual behavior go unquestioned. The norms themselves, or the formal aspects of behavior that embody them, remain out of any focus of attention. But when 
transgressions occur, norms are thematized, made explicit, articulated, characterized, and reasoned about. It is when things depart from the plan that the norms behind everyday ritual come to the surface. By contrast, in formal ritual, participants are aware of the event's special status and to some degree of its social meaning.

Early in my first extended field trip working with Kri speakers, I was blissfully unaware of the meaning of the Kri house. At a certain point I sat down, randomly, against the front wall of the house in the lowerinner quadrant, and my host joked, "Vòò nik tôo matààm [Grandfather Nick is a son-in-law!]." It drew much laughter, as any in-law joke should do. This is when I first became explicitly aware of the social significance of the Kri house's floor plan. The normally implicit had to be articulated. Since then, I have invited many Kri speakers to explain to me the social meaning of the house's spatial layout. Their accounts are more or less identical: family to the inner side, guests to the outer side, high status to the upper side, low status to the lower side. It is also agreed that these are not unbreakable rules but general tendencies.

The Kri speaker who joked about my sitting in the wrong part of the house treated my error as innocuous, if nevertheless worthy of remark. Perhaps as omni-ignorant ethnographer, I could not have known better. By contrast, I have heard sanction of outsiders who it seems should know better because they are regular overnight lodgers in these villages. These are the Vietnamese hiker-traders who engage in small-time trade throughout the area. A group of women once described to me, with disapproval, some of these men's lack of observance of the meaning of the Kri house's floor plan. Some of these guests simply walk unhindered around the house-for example, crossing to the inner side and entering the sia 'work and storage room' to look for a knife, a bowl, or the like. It is not that an outsider is forbidden from doing this. But when one does need to contravene the norm, whether as a guest crossing to the inner side or a household member crossing to the outer side, one ought to display an explicit orientation to the problematic nature of this little transgression.

The proper thing is to draw to the attention of those present that one needs to approach an inappropriate part of the house (requiring acknowledgment, thus as if asking permission) and to bow forward, lowering one's head and upper body while entering the problematic area. This marked manner of acting-creeping rather than walking-is an everyday ritual for displaying one's manners, one's willingness to cooperate with the local moral order. Failing to do so attracts moral condemnation. In passing moral judgments on their unmannered 
hiker-trader guests for failing to correctly "ritually regularize the risks" of these social encounters (Goffman 1976), the Kri women added that this behavior caused them to feel afraid of their guests. This supports the view that ritual is a means of social control (Bloch 1974). When people fail to observe required behavioral constraints, they become unpredictable and therefore menacing (see Burgess 1962). In the context of a moral order that needs upholding, they are, simply, "bad." Such expressions of disapproval are where cultural values are made explicit. ${ }^{11}$

Another case of sanctioning concerns the behavior of children. When guests are present, children are told by their elders not to cross to the outer side of the house, and especially not to cross to the upper-outer corner (rồòng). This admonishment is especially likely to occur during formal ritual occasions, when manner of action is generally in the foreground. On one occasion, I was the guest of honor at a hand-tying ceremony. As was proper, I was situated in the upper-outer corner of the house (fig. 2.11). At a certain point during the string-tying part of the event, three young girls who were seated across the other side of the fire pit (prùng kùùih) from me wanted to come to where I was in order to tie strings on my wrists. They had two paths available, the more direct one being to pass above the fire pit, and the other, to pass below it (fig. 2.12). As they set out to pass above, they were halted and sternly admonished by the man of the house, Non, who insisted they pass below the fire pit.

This redirection would have been unlikely in a context other than formal ritual-for example, if one of the girls was simply going to pass me a spoon while I ate my evening meal in my usual spot in the upperouter corner. But in a context in which "doing a cultural practice" was thematized (as is seen to be definitive of formal ritual), it was more important that things be (seen to be) done in the right way. ${ }^{12}$ As I argued earlier, in ritual, the manner of action becomes a sign in itself that may be inspected and evaluated for how well it conforms to local constraints. In a formal ritual setting such as this, when manner of action is a focus of attention, there is no doubt that Non's sanctioning behavior itself was a chance for him to display that he was a good Kri man by insisting that things be done right. His admonition to the girls served as a sign on multiple levels. Among other things, it was (1) an instruction for the girls to go the other way, (2) a sign that it would be "not good" to take the upper route in this situation, reiterating the moral norms at hand, and (3) a sign that he was a good Kri man for caring.

A subtler form of explication of the norms of spatial meaning in the house is people's daily insistence, in the most informal situations, that I 
(a)
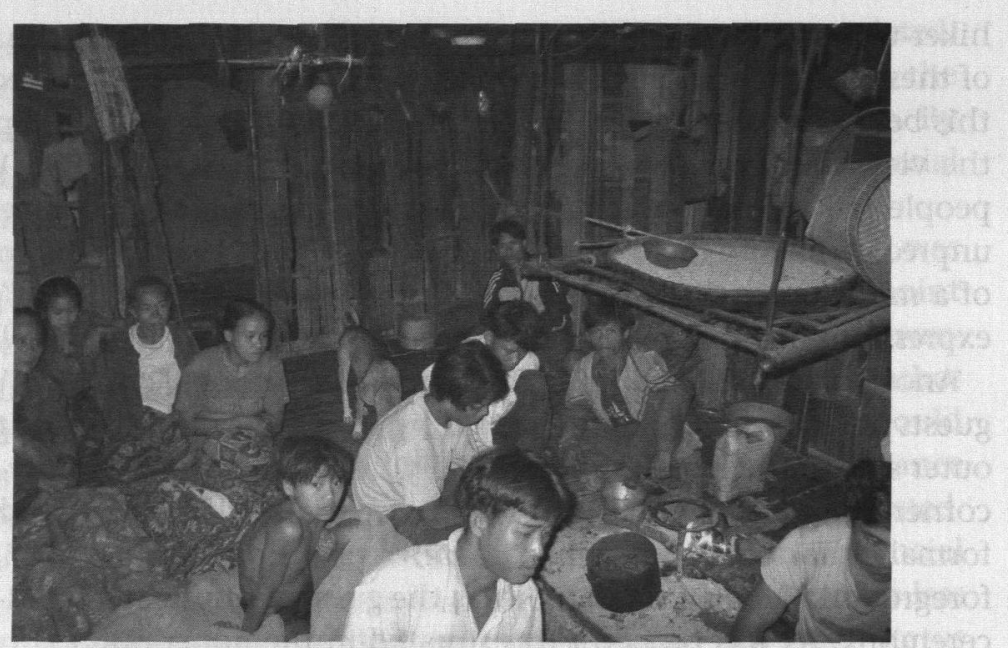

(b)

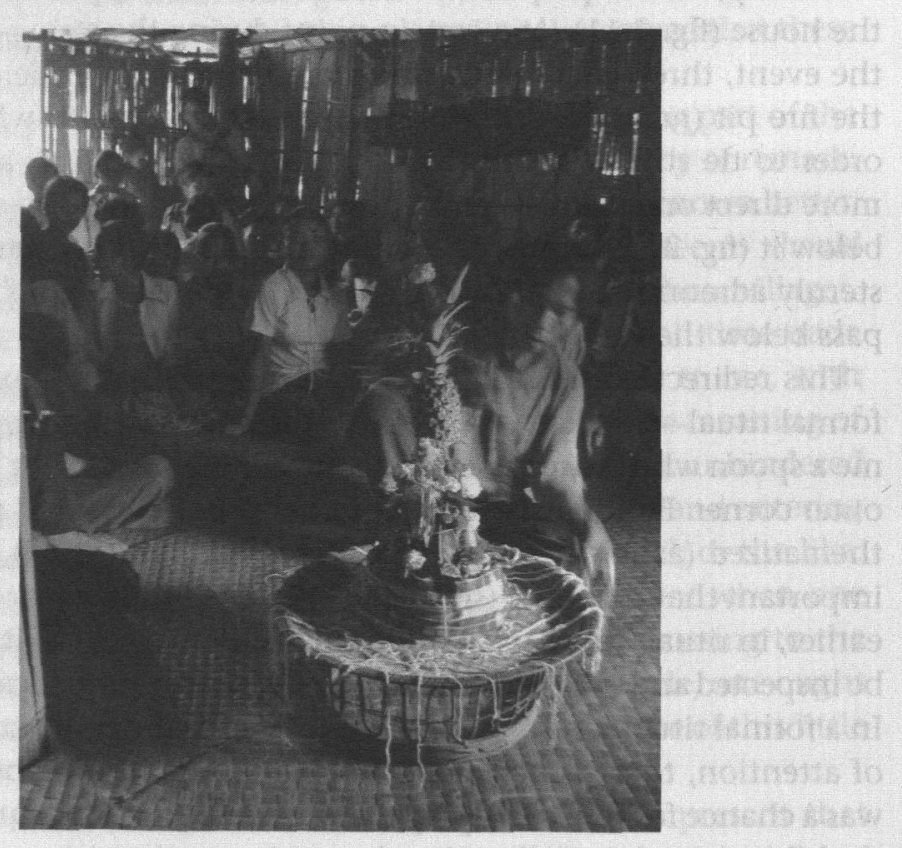

Figure 2.11. Two views from the rồng (upper-outer corner) during the ritual ceremony qjàk sii, or "tying of the hands." Note the position of the women to the outer side (left background) in both pictures. In the top image, a son-in-law of the household can be seen in the far background, wearing a black-and-white jacket. In the bottom photo, the strings being draped on this ritually decorated tray table will be tied one by one around the wrists of the guests of honor. 


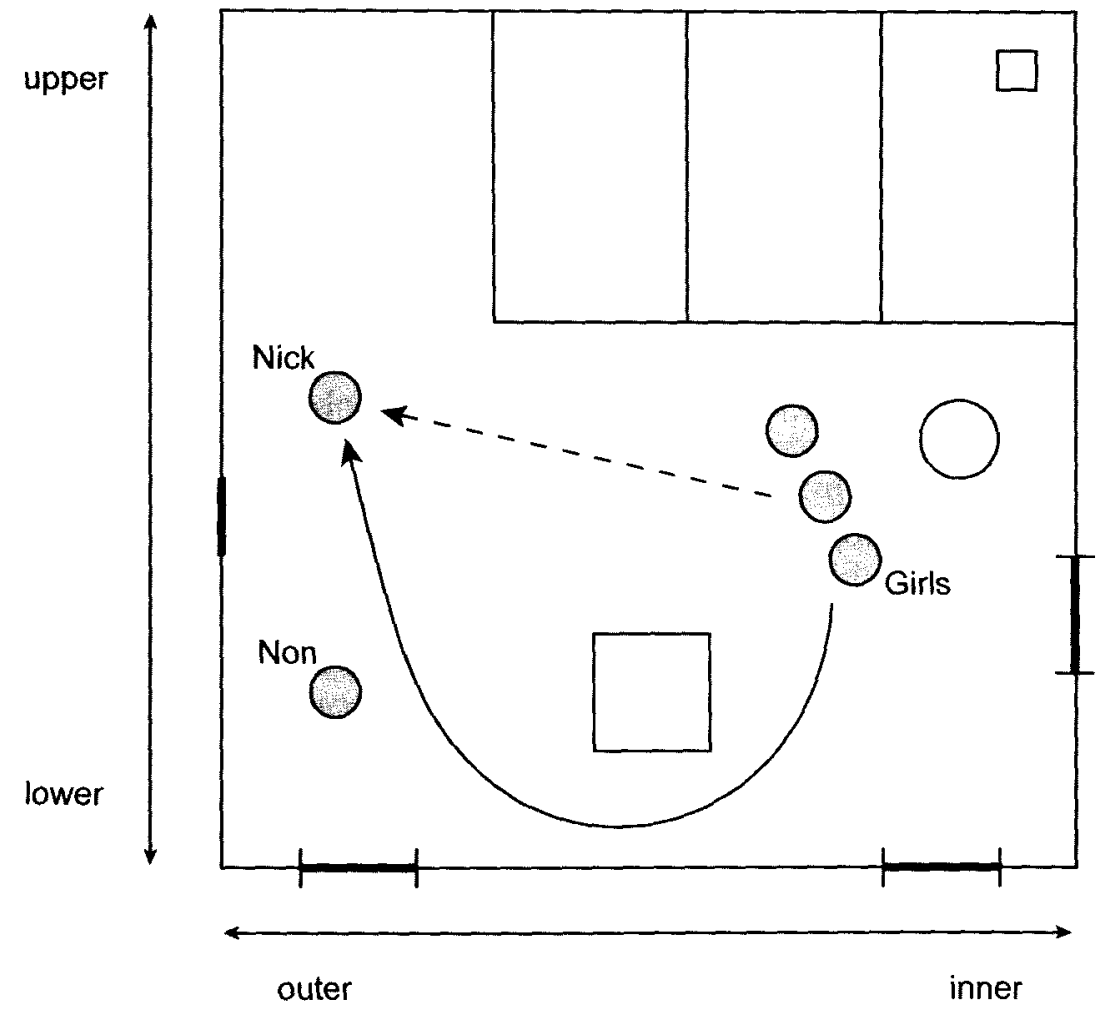

Figure 2.12. Example of sanction during ritual ceremony. Three girls need to cross the house to tie strings on Nick's wrists. As they set out to take the most direct route (dotted-line arrow), they are admonished by the man of the house (Non), who tells them to take the correct lower route (solid-line arrow).

sit in the upper-outer corner. If I sit close to the doorway, too far to the lower side, they usher me back (using the verb saaw 'ascend'). Again, this displays both the content of the norm itself and the degree to which people (want to be seen to) care about such norms' being followed. ${ }^{13}$

In each of these cases of sanction, my hosts and I participate in the regimentation of norms. People are morally obliged to orient themselves properly (i.e., to produce normative interpretants) toward the physical behavior that the house invites. The required discipline constrains the actual possibilities to a tiny fraction of the conceivable next moves. So the restraint (an institutionally founded constraint) that morality imposes is ritual(ized) in this way (Hauser 2006). All these examples constitute the substance of norms in the sense that (1) the practices 
are observed (evidence that people are disposed to follow the norms); (2) when they are not observed, this occasions surprise, sanction, or both; and (3) when they are observed, no such surprise or sanction is evinced (or, to be precise, if anyone oriented himself or herself toward observance of these norms with surprise or sanction, that itself would occasion surprise or sanction).

\section{Conclusion}

Why does a Kri son-in-law confine himself to the lower-inner edges of his father-in-law's house? Why is an honored guest ushered to the upperouter corner? Why, when a Kri man and wife sit down at home for a smoke after a long day in the fields, does the man sit on the outer corner of the fire pit while his wife sits toward the inner side? These everyday ritual behaviors provide ways of making public one's role or identity (whether given or given off; Goffman 1959) and to knowingly display how well one inhabits one's role or identity. This practical interpretation is at once a product of the individual's understanding of local norms, an index of those norms (constituting onlookers' evidence for them, whether as learners or users of the system), and a regimenting force for the cooperative, morally invested regularization of those norms. Practical interpretation of the semiotics of Kri residence allows community members to signal, relatively cheaply, their commitment to current norms, with motivators such as a moral order and an emotional intelligence to enforce it, driving people both to conform and to enforce conformity. To paraphrase the passage from Goffman quoted at the opening of this chapter, by interpreting the spatial meaning of the house in these normative ways, Kri speakers ritually regularize the risks and opportunities that co-presence provides, enforcing the standards generally enjoined in the community.

These everyday ritual practices substantiate and perpetuate social facts under the guise of brute facts (Searle 1995). No natural, causal law prevents a son-in-law from being in the upper-outer corner of his father-in-law's house, but for him it is truly as if he is physically subject to an external constraint (Durkheim 1982 [1895]: 59; Lévi-Strauss 1966: 221). Logically, Searle is right to say that money is just paper, worth only what we socially agree it is worth. But our firsthand experience is the same as the experience Kri speakers have with the social diagram inscribed in their house floor plan. No amount of logic will divorce our sense of investment in the worth of money-or the pressure upon the son-in-law to stay in his place. This gives ritual its power. 
As Goffman $(1967,1976)$ stressed, even the most mundane social encounter entails joint interpersonal commitment. Regardless of the nature of the exchange, one is obliged to pay attention to and engage with others, and one obliges others to pay attention and engage in return. Huxley's definition of ritual communication (1966b: 258) featured the twin objectives of "reducing damage" and "promoting bonding" in social relations. These are not so much about harmony as about politics (Bloch 1974), ${ }^{14}$ and everyday politics is delicate. Human inhibition and the morality associated with it mean that none but the most desperate Machiavellian intentions can be effected, baboonlike, with a random blow to the head in passing (Silk 2002). Human social interaction seldom if ever goes without some attention to everyday ritual, buckling to its constraints as in formal ritual. The difference is whether the manner or formal execution of action is a focus of participants' attention. In both cases, the manner of action is available for moral evaluation. In this way, ritual behavior is both weapon and shield for handling the political and moral delicacy of social co-presence that characterizes human interaction.

\section{Notes}

I received useful suggestions on written versions of this paper from Grant Evans, Steve Levinson, Gunter Senft, Ellen Basso, and three anonymous reviewers. I also received careful commentary from Paul Kockelman, who helped me clarify a number of points. Subsequent input from my fellow participants in Sintra helped me further improve this work. Many thanks to these colleagues. Deficiencies are due to me alone. I gratefully acknowledge Ludy Cilissen's expert assistance with the illustrations and the Max Planck Society's support of the research, as well as the Wenner-Gren Foundation's role in funding and hosting the Sintra symposium. Photographs are by the author. I thank the Krispeaking community for welcoming me into their world and allowing me to publicize it. This chapter is dedicated to Grant Evans, with thanks for a decade of generosity, intellectual and otherwise.

1. The term "ritual" is used in the literature for at least three kinds of phenomena: ritualized communicative behavior in an ethological sense (Huxley 1966b), which captures all linguistic and other human symbolic behavior 
(Leach 1966: 404; Watts 1999); formal ritual, or "symbolic actions relating to the sacred" (Firth 1972: 3)-that is, more socially marked events such as weddings, initiations, swearings-in, and other rites of passage; and everyday ritual, the far more casual yet still formal procedures "of a communicative but arbitrary kind, having the effect of controlling or regularizing a social situation" (Firth 1972: 3)-for example, greetings ("Good morning") and politeness formulas ("Thank you"). For some, the category of everyday ritual permeates well beyond these easily recognized little exchanges. Goffman $(1959,1967)$, for example, pointed to the ritual nature of just about every move we make in social interaction. Whether or not scholars of ritual collectively wish to include under ritual communication both a wedding ceremony and a chat between cousins at the reception later on, we should be able to characterize the similarities and differences between those things that have been described as ritual to date and keep them terminologically distinct.

2. Thanks to Federico Rossano for pointing out Sacks's phrase to me.

3. I use the term "illusion" to avoid the agency implied by the word "deception" in the quoted passage.

4. Learned disgust (e.g., at certain foods) is a good case of transposing the institutional to the brute (or social to causal, or cognitive to behavioral).

5. This kind of unquestioning acceptance is arguably an innate form of docility (Simon 1990). Recent researchers evoke this as a key mechanism in cultural evolution and cultural learning: "The psychology of social learning should plausibly be arranged so that people have a strong tendency to adopt the views of the majority of those around them" (Richerson and Boyd 2005: 122; see also Boyd and Richerson 2005; Gergely and Csibra 2006). It appears to be adaptive and economical to adopt the practices of one's consociates (i.e., those with whom we identify) without asking why those things are (1) to be done and (2) to be done in that way. Although a cultural practice might be maladaptive (as some cultural practices are), chances are that if it has survived to be passed on, it is not maladaptive, and it may even be positively adaptive. At least, no (immediate) harm will likely be done in taking it on. Inconveniences ranging from keeping one's elbows off the dinner table to lying still while one's brow is cut to the bone are all, it seems, readily accepted by those who are inconvenienced by them.

6. The inconvenience of ritual is far more apparent in formal rituals such as subincision, scarification, and circumcision, but in everyday ritual it is still there. This is especially clear when we compare ourselves with other beasts and note that only we humans are capable of inhibiting our compulsions to a degree sufficient to, for instance, remain in the dentist's chair for the duration of an appointment or refrain from reaching over in the subway and grabbing someone else's food when we are hungry (see Hauser 2006). 
7. There is no fixed or absolute left-right mapping of the inner-outer axis. Some houses have the inner side on the left (e.g., fig. 2.1), and others, on the right (e.g., fig. 2.9). Compare the images in figure 2.4 , where the ladders leading up at the houses' outer sides are opposite to each other.

8. Also following Kockelman (2006), I am interested in affordances and instruments as among those aspects of our world that are semiotic (see also Gibson 1979) and through which we may observe people interpreting their residential world. There is much to say regarding the affordances incorporated into the Kri house. To pick just one, there is the set of possibilities afforded by split-bamboo flooring: One may spit and drop rubbish through the floor at will. Description of the incorporation of affordances into the complex instrument called the krnooq 'house' is reserved for a more complete ethnography of $\mathrm{Kri}$ residence.

9. Returning to the normally tacit, unthematized nature of everyday norms and rituals, Goffman (1963: 2-3) went on: "Typically, we do not become aware that we have made these demands or aware of what they are until an active question arises as to whether or not they will be fulfilled." Stigma arises when "usualness" is noticeably absent.

10. Drinking has to be done in a certain order, because there is only one vessel to drink from. As for the serving of after-meal tea, its order is strictly by rank and is determined with great seriousness.

11. This kind of explicit talk is part of the broader set of mechanisms for enculturation beyond mere practical-behavioral habituation. Although Bourdieu's theory of practice $(1977,1990)$ is often taken to deliver culture "without articulation," it is clear from Bourdieu's work that it matters a great deal how people talk about their cultural world (Goddard 2002: 69; Hanks 2005).

12. Accordingly, during formal rituals among the Kri, I have observed those in charge bicker about "the right way to do it," or to self-sanction, saying that they themselves don't know how to do it. This is especially common among younger people during phases of the qjàk sii ritual in which one is required to chant short conventional phrases, which few people seem to have memorized correctly. This is not to say that the norms are absent in less formal contexts but merely that they are relatively relaxed and unthematized. But this is only relative. Some aspects of behavior and meaning of the house are strictly observed. For example, the constraint against a son-in-law or daughter-in-law being on the outer side of the house, especially in the outer-upper corner, is strong and laden with emotional response. People report that they simply could not bring themselves to step into that part of their parents-in-law's house. 
13. There are practical issues, too. Wherever I am sitting, others will not want to sit "above" me, so if I sit too far toward the lower end of the house, an open area of house space becomes unusable for others.

14. This is in line with Owings and Morton's (1998) model of animal vocal communication (following Krebs and Dawkins 1984). Their model is constructed on an assessment-management mechanism. The individual's powers of assessment (not necessarily dedicated to social interaction) are presupposed and exploited in the formulation of communicative behaviors in order to change the world in ways desired by the formulator of a message. In other words, what senders do is driven by what they anticipate receivers will do in response. 